\title{
Quantitative proton MRS of cerebral metabolites in laminin $\alpha 2$ chain deficiency
}

\author{
Knut Brockmann ${ }^{\mathrm{a}, *}$, Peter Dechent ${ }^{\mathrm{b}, 1}$, Carsten Bönnemann ${ }^{\mathrm{a}, 2}$, \\ Gudrun Schreiber ${ }^{\mathrm{a}, 3}$, Jens Frahm ${ }^{\mathrm{b}}$, Folker Hanefeld ${ }^{\mathrm{a}}$ \\ a Department of Paediatrics and Paediatric Neurology, Georg August University, 37075 Göttingen, Germany \\ ${ }^{\mathrm{b}}$ Biomedizinische NMR Forschungs GmbH am Max Planck Institut für biophysikalische Chemie, 37070 Göttingen, Germany
}

Received 16 June 2006; received in revised form 24 October 2006; accepted 5 November 2006

\begin{abstract}
Congenital muscular dystrophy (CMD) due to merosin (laminin $\alpha 2$ chain) deficiency is an autosomal recessively inherited disorder characterized by severe muscular weakness and hypotonia from birth on. Brain involvement is the rule and characterized by variable T2 hyperintensities of white matter which appears swollen on cranial MRI. The pathophysiology of these white matter changes is not clear. In five patients with laminin $\alpha 2$ deficient CMD we performed short-echo time localized proton MRS with determination of absolute metabolite concentrations in grey and white matter. In affected white matter, a consistent pattern of metabolites was detected comprising reduced concentrations of $N$-acetylaspartate and $N$-acetylaspartylglutamate, creatine, and phosphocreatine, and to a milder degree of choline-containing compounds. In contrast, concentrations of myo-inositol were in the normal range. Spectra of cortical and subcortical grey matter were normal. The observed metabolite profile is consistent with white matter edema, that is reduced cellular density, and relative astrocytosis. This interpretation is in line with the hypothesis that laminin $\alpha 2$ deficiency results in leakage of fluids across the blood-brain barrier and a histopathological report of astrocytic proliferation in CMD.
\end{abstract}

(C) 2006 Elsevier B.V. All rights reserved.

Keywords: Congenital muscular dystrophy; Laminin $\alpha 2$ chain; Leukoencephalopathy; MR spectroscopy

\section{Introduction}

Laminin, a complex glycoprotein found extracellularly in the basement membranes, consists of three different polypeptide chains, a heavy alpha chain and

\footnotetext{
${ }^{*}$ Corresponding author. Tel.: +49 55139 6210; fax: +49 55139 6252.

E-mail address: kbrock@med.uni-goettingen.de (K. Brockmann).

${ }^{1}$ Present address: MR-Research in Neurology and Psychiatry, Georg August University, 37075 Göttingen, Germany.

2 Present address: Division of Neurology, The Children's Hospital of Philadelphia, and University of Pennsylvania School of Medicine, Philadelphia, USA.

${ }^{3}$ Present address: Department of Neuropaediatrics, Klinikum Kassel, Kassel, Germany.
}

two light chains, $\beta$ and $\gamma$. They are bound to each other by disulfide bonds forming a cross-shaped molecule. The alpha-2 $(\alpha 2)$ chain is a subunit of laminin-2 (merosin) and laminin-4 (s-merosin). Laminin is thought to mediate the attachment, migration, and organization of cells into tissues during embryonic development by interacting with other extracellular matrix components. Tissues containing laminin comprise placenta, striated and cardiac muscle, peripheral nerve, meninges, chorioid plexus, and other regions of the brain [1]. In 1994, a lack of merosin, the laminin $\alpha 2$ chain, was demonstrated in patients with the classical non-Fukuyama type congenital muscular dystrophy (CMD) [2]. Subsequently, mutations in the $L A M A 2$ gene on chromosome $6 \mathrm{q} 22-\mathrm{q} 23$ were detected 
in patients with laminin $\alpha 2$ deficient CMD (MDC1A, MIM \#607855) [3].

Clinical features in complete deficiency of laminin $\alpha 2$ include severe muscular hypotonia and weakness in the first weeks of life with slow improvement, but inability of independent ambulation in most cases [4]. Congenital contractures are common, feeding difficulties and respiratory problems may occur. Creatine kinase levels are markedly raised. Extramuscular involvement includes demyelinating peripheral neuropathy and striking white matter changes on cranial MRI. Widespread diffuse T2 hyperintensity of swollen appearing white matter is a characteristic finding after the first months of life [5]. Some of the patients have macrocephaly. However, clinical symptoms of cerebral involvement are usually rather mild. Intelligence is normal in most children, and epilepsy may occur in about $30 \%$ of patients [4]. In few patients, a range of structural malformations was demonstrated comprising occipital agyria, polymicrogyria, and hypoplasia of pons and vermis clinically accompanied by more severe mental and motor disability [5-8]. Recent reports described an expanding phenotype of laminin $\alpha 2$ deficiency with later onset which shows slowly progressive weakness of limb-girdle muscles. At least $25 \%$ of these patients achieve independent ambulation and several patients with LAMA2 mutations reveal normal MRI [9].

In general, the striking discrepancy between marked white matter MRI signal alterations of cerebral white matter and only subtle clinical signs of brain dysfunction is well recognized. To date, the pathophysiology of the white matter changes remains unclear. In this study, we used localized proton magnetic resonance spectroscopy (MRS) with absolute quantification of cerebral metabolites to further characterize cerebral tissue abnormalities in patients with MDC1A.

\section{Patients and methods}

We studied five boys with MDC1A whose ages ranged from 10 months to 14 years at MRS. Table 1 summarizes the clinical, neuroradiological, and histological features. In patients 1,2 , and 4 , diagnosis of complete or near-complete laminin $\alpha 2$ deficiency was based on immunohistochemical investigations of a biopsy from the quadriceps muscle. Muscle biopsies in patients 3 and 5 had been performed before immunohistochemistry for laminin $\alpha 2$ was available. In patient 3, laminin a2 deficiency was demonstrated in an additional skin biopsy. Immunocytochemical studies were performed using antibodies to the $80 \mathrm{kDa}$ fragment of merosin (Anti-Human Merosin, Gibco-BRL, Berlin, Germany) in patients 1, 2, 3, and 4. Additionally, a second antibody (NCL Merosin, Novocastra, Newcastleupon-Tyne, UK) was used in patients 1,2 , and 3 . Laminin $\alpha 2$ deficiency was complete in patients 2 and 4 , and near-complete in patients 1 and 3 . Patient 5 was included in this study as his clinical, neuroradiological, and histological features clearly pointed to MDC1A. Mutation analysis of the LAMA2 gene was not performed in our patients, as this assay currently is not readily available.

MRI revealed signal alterations of supratentorial white matter in all patients to a varying degree. Diffuse extensive widespread $\mathrm{T} 2$ hyperintensity of white matter was present in patients 1 (Fig. 1), 4, and 5. White matter appeared swollen in these patients, and head circumference was at the 90th, 98th, and above the 98th centile, respectively. Macrocephaly in patient 5 was present at birth already. MRI in patients 2 and 3 showed patchy T2 hyperintensities in supratentorial white matter that were extensive and widespread in patient 2 (Fig. 2) and confined to small frontal and occipital areas in patient

Table 1

Clinical, immunohistochemical, and neuroradiological features in five patients with laminin $\alpha 2$ chain deficiency

\begin{tabular}{|c|c|c|c|c|c|}
\hline Patient & 1 & 2 & 3 & 4 & 5 \\
\hline Sex & $\mathrm{M}$ & $\mathrm{M}$ & M & M & $\mathrm{M}$ \\
\hline Affected sibling & - & - & - & - & - \\
\hline Age at onset & Birth & Birth & Birth & Birth & Birth \\
\hline Max. motor milestone & Walking & Sitting & Sitting & Sitting & Sitting \\
\hline Contractures & + & + & + & + & + \\
\hline Head circumference (centile) at birth & 75 & n.a. & n.a. & n.a. & $>98$ \\
\hline Head circumference (centile) at MRS & 90 & 75 & $>98$ & 98 & $>98$ \\
\hline Learning difficulties & - & - & + & - & - \\
\hline Epilepsy & - & + & - & - & - \\
\hline Nerve conduction velocity & $\mathrm{n}$ & $\mathrm{n}$ & n.a. & Reduced & Reduced \\
\hline Highest CK level & $\uparrow$ & $\uparrow$ & $\uparrow \uparrow$ & $\uparrow$ & $\uparrow$ \\
\hline Age at biopsy & $3 \mathrm{w}$ & $1 \mathrm{y}, 9 \mathrm{y}$ & $3 y$ & $2 \mathrm{~m}, 10 \mathrm{y}$ & $6 y$ \\
\hline Laminin $\alpha 2$ deficiency demonstrated in & Muscle & Muscle & Skin & Muscle & n.a. \\
\hline Degree of laminin $\alpha 2$ deficiency & Near-comp. & Complete & Near-comp. & Complete & n.a. \\
\hline MRI WM changes & $\mathrm{C}$ & $\mathrm{P}$ & $\mathrm{P}$ & $\mathrm{C}$ & $\mathrm{C}$ \\
\hline Age at MRS & $10 \mathrm{~m}, 2 \mathrm{y} 7 \mathrm{~m}$ & $7 \mathrm{y} 2 \mathrm{~m}$ & $9 y 6 \mathrm{~m}$ & $10 \mathrm{y} 3 \mathrm{~m}$ & $14 \mathrm{y} 4 \mathrm{~m}$ \\
\hline
\end{tabular}

M, male; CK, creatine kinase; $\uparrow,>100 \mathrm{U} / \mathrm{L} ; \uparrow \uparrow,>1000 \mathrm{U} / \mathrm{L}$; WM, white matter; +, present; -, absent; n, normal; n.a., not available; near-comp., near-complete; $\mathrm{C}$, confluent; $\mathrm{P}$, patchy. 


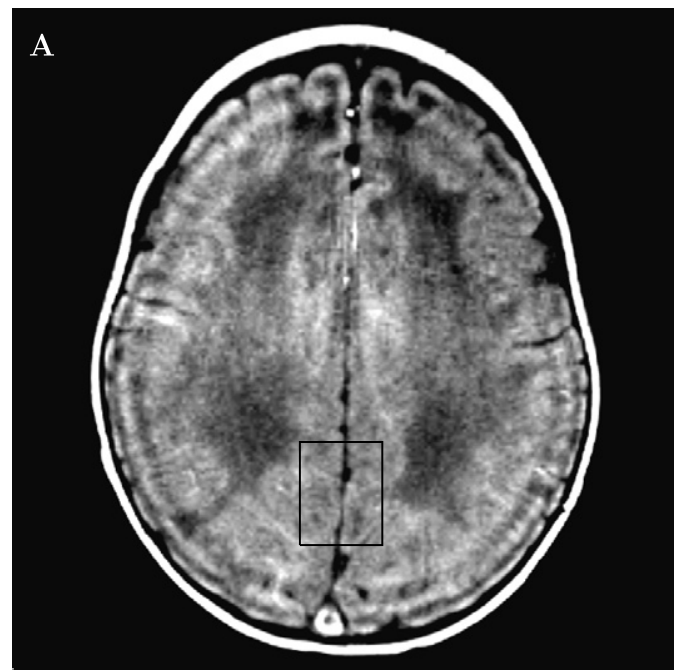

$\mathrm{D}$
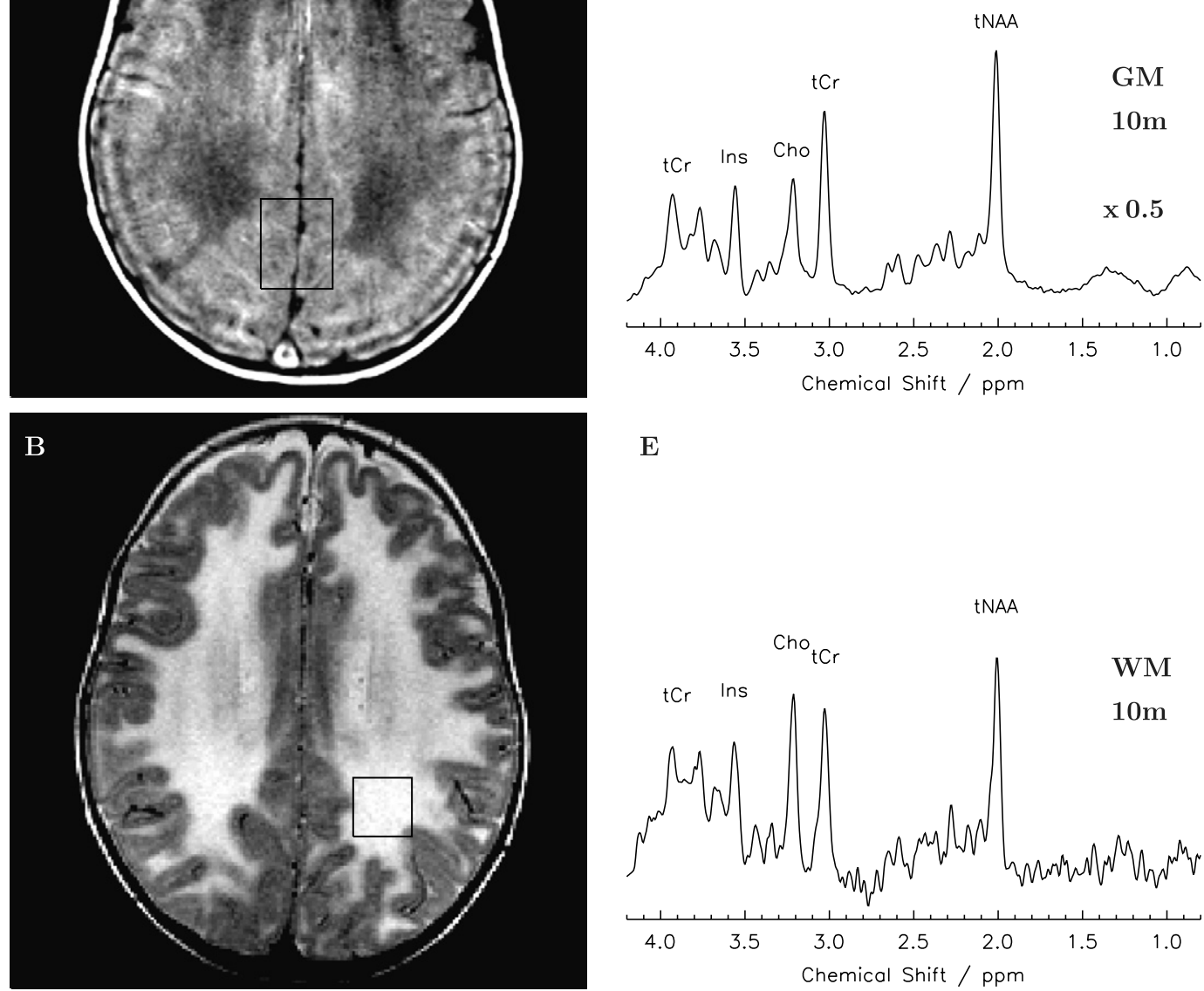

$\mathbf{E}$
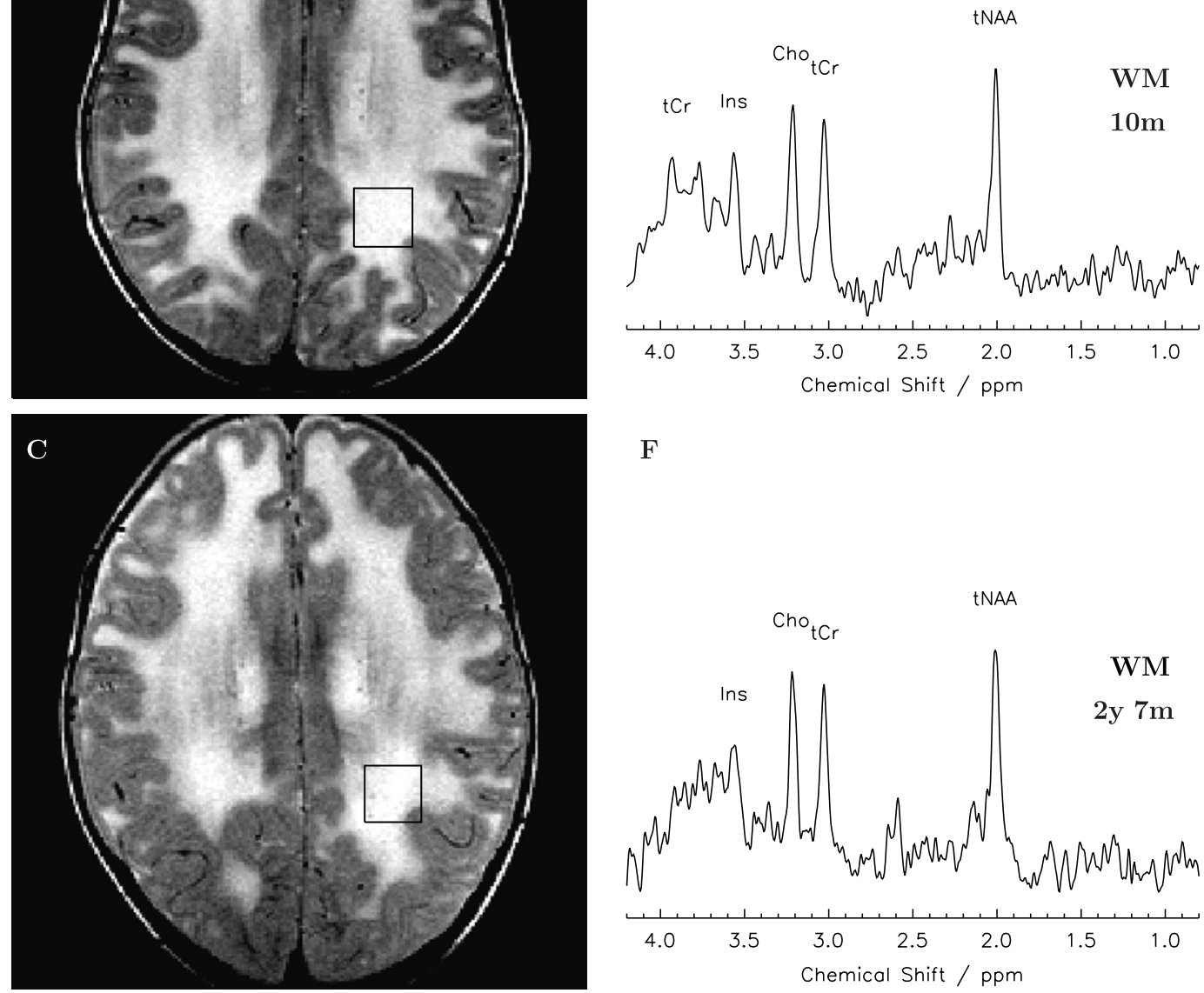

F

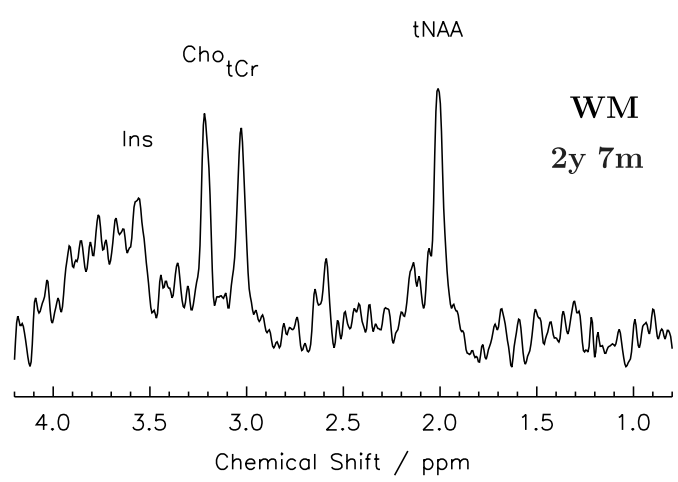

Fig. 1. Cerebral MRI and proton MRS of patient 1 with laminin $\alpha 2$ CMD at 10 months and 2 years 7 months of age. (A and D) T1-weighted MRI and MRS (STEAM, TR/TE/TM $=6000 / 20 / 10 \mathrm{~ms}$ ) of paramedian parietal gray matter, (B and E) T2-weighted MRI and MRS of left parietooccipital white matter at 10 months of age and $(\mathrm{C}$ and $\mathrm{F})$ at 2 years and 7 months of age, respectively.

3 (Fig. 3). Head circumference was at the 75 th and above the 98 th centile, respectively. No overt cortical dysplasia was present in any of the patients.
Written informed consent was obtained from the patients' parents. Combined MRI/MRS studies were carried out at $2.0 \mathrm{~T}$ (Siemens Magnetom Vision, 

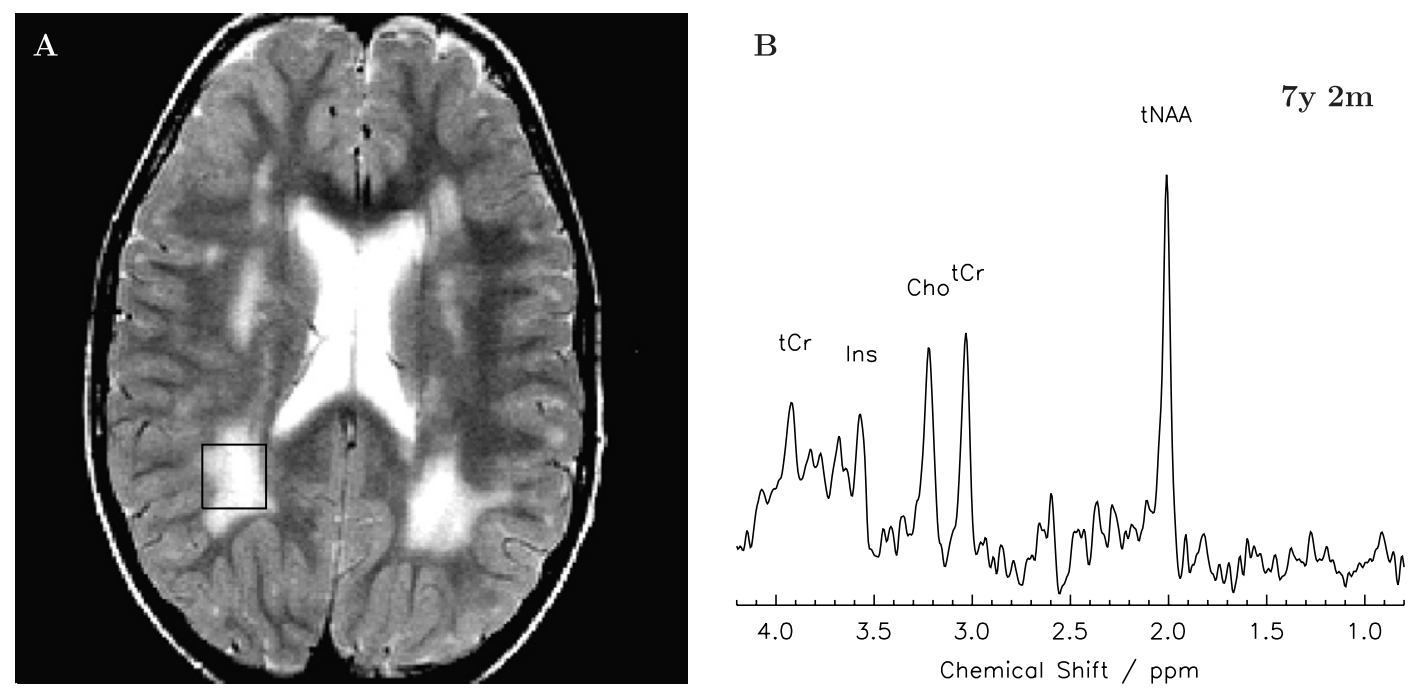

Fig. 2. Cerebral MRI and proton MRS of patient 2 with laminin $\alpha 2$ CMD at 7 years 2 months of age. (A) T2-weighted MRI and (B) MRS of right parieto-occipital white matter.

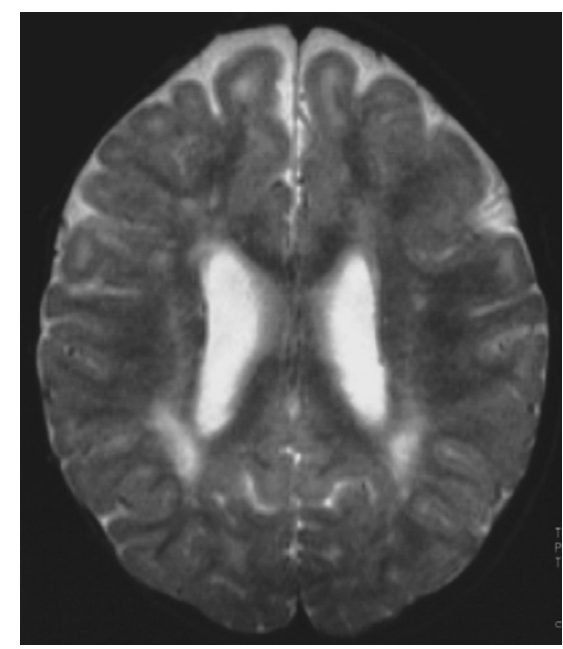

Fig. 3. T2-wighted MRI (1.5 T) of patient 3 at 4 years of age showing patchy white matter alterations.

Erlangen, Germany) using the standard imaging headcoil. Fully relaxed short-echo time proton MR spectra were acquired by means of a single-voxel stimulated echo acquisition mode (STEAM) localization sequence (TR/TE/TM $=6000 / 20 / 10 \mathrm{ms,} 64$ accumulations) as described previously [10]. Volumes of interest (VOI) were selected from T1-weighted (3D FLASH) and T2weighted (FSE) images, with sizes ranging from 4.1 to $18 \mathrm{ml}$. VOI locations included one or two regions in affected white matter (frontal, parieto-occipital) and paramedian parietal grey matter in all patients. In addition, basal ganglia were examined in patient 4 .

Spectral evaluation and quantification of absolute metabolite concentrations were accomplished with use of LCModel [11]. The approach represents a userindependent fitting routine based on a library of calibrated model spectra of individual compounds and therefore avoids bias due to manual post-processing. Because of the use of an external reference, the method is free from putative changes of the internal water proton signal. Moreover, the quantification is neither compromised by $\mathrm{T} 1$ saturation (very long repetition time) nor markedly affected by $\mathrm{T} 2$ attenuation (very short echo time). Metabolite concentrations are therefore expressed in $\mathrm{mM}$, i.e., $\mathrm{mmol}$ per liter VOI, without corrections for CSF contributions and residual T2 relaxation effects. Major detectable metabolites include the neuroaxonal markers [12] $\mathrm{N}$-acetylaspartate and $\mathrm{N}$-acetylaspartylglutamate (tNAA), creatine, and phosphocreatine ( $\mathrm{tCr}$ ) as ubiquitous compounds linked to energy metabolism [13], choline-containing compounds (Cho) involved in membrane turnover [14], the glial (astrocytic) marker [15] myo-inositol (Ins), and lactate (Lac) as the intermediate product of nonoxidative glucose consumption. Previous studies of regional age dependencies of cerebral metabolites provided age-matched controls for the evaluation of individual pathological alterations [16]. Values different from the mean normal value by $\geqslant 2$ standard deviations (SD) were regarded as abnormal. Further details of MRS data acquisition and spectral evaluation have been described elsewhere [17].

\section{Results}

Fig. 1 shows representative MR images and spectra of grey and white matter of patient 1 with extensive diffuse leukoencephalopathy at 10 months and 31 months of age. Fig. 2 shows a complementary image and white matter spectrum of patient 2 with patchy white matter alterations. Quantitative analyses of absolute metabolite concentrations in white matter are summarized in Table 2. Patient 3, who showed the 
Table 2

Cerebral metabolite concentrations $(\mathrm{mM})$ in white matter and aged-matched controls [16]

\begin{tabular}{|c|c|c|c|c|c|c|c|}
\hline Patient & Age & Region $^{\mathrm{a}}$ & tNAA & $\mathrm{tCr}$ & Cho & Ins & $\mathrm{Lac}$ \\
\hline \multirow[t]{2}{*}{1} & $10 \mathrm{~m}$ & LPO & $3.6^{*}$ & $3.9^{*}$ & $1.3^{*}$ & 3.8 & 0.9 \\
\hline & & RPO & $4.3^{*}$ & $3.9^{*}$ & $1.3^{*}$ & 3.9 & 1.0 \\
\hline \multicolumn{3}{|c|}{ Control $(<1 \mathrm{y}, n=10)$} & $6.2 \pm 0.8$ & $5.4 \pm 0.5$ & $2.0 \pm 0.2$ & $4.0 \pm 0.5$ & - \\
\hline & $2 \mathrm{y} 7 \mathrm{~m}$ & LPO & $4.3^{* *}$ & $3.1 * *$ & $1.3^{*}$ & 3.3 & - \\
\hline & & $\mathrm{RF}$ & $3.5^{* *}$ & $3.3^{* *}$ & $1.3^{*}$ & 3.8 & - \\
\hline \multicolumn{3}{|c|}{ Control $(2-<5$ y, $n=12)$} & $7.2 \pm 0.7$ & $5.0 \pm 0.4$ & $1.9 \pm 0.2$ & $3.7 \pm 0.6$ & - \\
\hline \multirow[t]{2}{*}{2} & $7 \mathrm{y} 2 \mathrm{~m}$ & LF & $5.4^{*}$ & 4.3 & 1.5 & 3.8 & - \\
\hline & & RPO & $5.3^{*}$ & $3.9^{*}$ & 1.5 & 3.6 & - \\
\hline 3 & $9 y 6 \mathrm{~m}$ & RPO & 6.5 & 5.1 & 1.2 & 3.4 & - \\
\hline \multicolumn{3}{|c|}{ Control $(5-<10 \mathrm{y}, n=7)$} & $6.9 \pm 0.6$ & $4.9 \pm 0.4$ & $1.6 \pm 0.3$ & $3.7 \pm 0.6$ & - \\
\hline \multirow[t]{2}{*}{4} & $10 \mathrm{y} 3 \mathrm{~m}$ & LPO & $5.0 * *$ & $3.2 * *$ & $1.0^{*}$ & 3.5 & - \\
\hline & & RPO & $5.6^{*}$ & $3.4^{*}$ & $1.2^{*}$ & 2.5 & 1.8 \\
\hline \multirow{2}{*}{5} & $14 \mathrm{y} 4 \mathrm{~m}$ & LPO & $5.3^{* *}$ & $2.9^{* *}$ & $1.0^{*}$ & 2.2 & - \\
\hline & & RPO & $4.8^{* *}$ & $2.2^{* *}$ & $0.8^{* *}$ & 1.8 & - \\
\hline \multicolumn{3}{|c|}{ Control (10-18y, $n=12)$} & $7.9 \pm 0.6$ & $4.8 \pm 0.4$ & $1.6 \pm 0.2$ & $3.9 \pm 1.2$ & - \\
\hline
\end{tabular}

$* \geqslant 2$ SD from control; $* * \geqslant 4$ SD from control.

${ }^{\text {a }}$ L, left; R, right; F, frontal; P, parietal; O, occipital.

Table 3

Cerebral metabolite concentrations $(\mathrm{mM})$ in grey matter and aged-matched controls [16]

\begin{tabular}{|c|c|c|c|c|c|c|c|}
\hline Patient & Age & Region $^{\mathrm{a}}$ & tNAA & $\mathrm{tCr}$ & Cho & Ins & Lac \\
\hline 1 & $10 \mathrm{~m}$ & PMP & $7.7^{*}$ & 6.7 & 1.4 & 5.3 & - \\
\hline \multicolumn{3}{|c|}{ Control $(<1 \mathrm{y}, n=6)$} & $6.1 \pm 0.7$ & $5.5 \pm 0.7$ & $1.4 \pm 0.3$ & $4.8 \pm 0.7$ & - \\
\hline & $2 \mathrm{y} 7 \mathrm{~m}$ & PMP & 8.5 & 6.3 & 1.2 & 5.0 & - \\
\hline \multicolumn{3}{|c|}{ Control $(2-<5$ y, $n=16)$} & $8.2 \pm 0.9$ & $6.4 \pm 0.7$ & $1.1 \pm 0.2$ & $4.7 \pm 0.4$ & - \\
\hline 2 & $7 \mathrm{y} 2 \mathrm{~m}$ & PMP & 8.4 & 6.5 & 1.2 & 4.7 & - \\
\hline 3 & $9 y 6 m$ & PMP & 8.2 & 6.5 & 1.0 & 4.0 & 0.8 \\
\hline \multicolumn{3}{|c|}{ Control $(5-<10 \mathrm{y}, n=13)$} & $8.2 \pm 0.9$ & $6.2 \pm 0.5$ & $1.2 \pm 0.2$ & $4.6 \pm 0.7$ & - \\
\hline 4 & $10 \mathrm{y} 3 \mathrm{~m}$ & PMP & 8.5 & 7.1 & 1.0 & 4.5 & - \\
\hline 5 & $14 \mathrm{y} 4 \mathrm{~m}$ & PMP & 9.1 & 6.1 & 1.2 & 4.9 & - \\
\hline \multicolumn{3}{|c|}{ Control $(10-18 \mathrm{y}, \mathrm{n}=22)$} & $9.0 \pm 0.8$ & $6.5 \pm 0.5$ & $1.1 \pm 0.2$ & $4.3 \pm 0.6$ & - \\
\hline 4 & $10 \mathrm{y} 3 \mathrm{~m}$ & BG & 6.4 & 6.8 & 1.2 & 3.8 & - \\
\hline \multicolumn{3}{|c|}{ Control $(10-18 y, n=5)$} & $8.0 \pm 0.9$ & $7.7 \pm 0.9$ & $1.8 \pm 0.4$ & $3.3 \pm 0.8$ & - \\
\hline
\end{tabular}

$* \geqslant 2$ SD from control

a PMP: paramedian parietal, BG: basal ganglia.

mildest $\mathrm{T} 2$ signal alterations of all five patients, was the only one with all metabolites within the normal range.

In general, metabolic changes in white matter showed a characteristic pattern consisting of a significant reduction of tNAA and $\mathrm{tCr}$ as well as a milder decrease of Cho and normal Ins values. This profile was found in at least one white matter region investigated in four of five patients. The decreases of tNAA ranged from 2.2 to $5.3 \mathrm{SD}$ of mean control, and $\mathrm{tCr}$ was reduced by 3 to $6.5 \mathrm{SD}$. A significant reduction of Cho by 2 to 4 SD was found in three patients, whereas patients 2 and $3 \mathrm{had}$ a decrease of Cho by only 0.3 to $1.3 \mathrm{SD}$. In contrast, Ins was normal in all patients in all 11 white matter regions investigated. A slight increase of Lac was observed in three of the examined white matter regions.
Quantitative MRS of cortical grey matter (all patients) and basal ganglia (patient 4 only) revealed metabolite concentrations within the normal range for all metabolites (Table 3). The only exception was an increased concentration of tNAA in cortical grey matter of patient 1 at the time of his first investigation (age 10 months). At follow-up (2 years 7 months) the tNAA level was within the normal range.

\section{Discussion}

Using quantitative MRS in five patients with MDC1A we detected most pronounced changes of metabolites in cerebral white matter in those patients with more extensive widespread and diffuse white matter 
signal alterations on MRI (patients 1, 4, and 5). In contrast, MRS was normal (patient 3) or revealed merely mild metabolite abnormalities (patient 2) in both patients with only mild and patchy T2-hyperintensities. On the other hand, MRS abnormalities did not correlate to the severity of muscular weakness, signs of cerebral dysfunction, or degree of laminin $\alpha 2$ deficiency, as evident from Table 1 . In four patients with white matter alterations on T2-weighted MRI a consistent pattern of metabolite changes was detected comprising decreases of tNAA, tCr, and to a milder degree also of Cho. In contrast, Ins concentrations were in the normal range. There are two possible explanations for this metabolic profile. First, the alterations are consistent with, but not specific for neuroaxonal loss as suggested by the low levels of tNAA and tCr. Alternatively, the same pattern may be the result of a dilution of all metabolites, or more precisely of a generally reduced cellular density, which is accompanied by a relative astrocytic proliferation as indicated by the preserved level of Ins.

The pathophysiology of white matter alterations in MDC1A is not completely understood. Two lines of evidence suggest an important role for laminin $\alpha 2$ in CNS myelination and stability of cerebral whiter matter. First, a leakage of water across the blood-brain barrier has been presumed to result from laminin $\alpha 2$ deficiency. In a study combining immunohistochemical and specific electron microscopy techniques laminin $\alpha 2$ was localized in the normal human brain to the basal lamina of all cerebral blood vessels, whereas choroid plexus and meningeal blood vessels showed no immunoreactivity [18]. This observation led to the hypothesis, that laminin $\alpha 2$ may be important for the selective filtration capacity of the blood-brain barrier. Subsequently, it has been postulated, that the lack of laminin $\alpha 2$ in cerebral vessels of children with MDC1A may cause impaired selective filtration, leading to leakage of plasma components [18] and that the increased T2 relaxation time in MRI may be attributed to increased water content in white matter [19].

Second, recent investigations of oligodendrocyte differentiation and myelin membrane formation in oligodendrocytes grown in cell culture showed that laminin-2 substrates dramatically enhance myelin membrane formation. This effect is probably mediated via $\beta 1$ integrins [20]. It has been concluded that laminin $\alpha 2$ acts to enhance the production and spreading of the developing myelin sheath along and around the axon [20]. A critical role for laminin $\alpha 2$ in CNS myelination has been demonstrated in laminin $\alpha 2$ deficient mice, where a reduced thickness of the corpus callosum, a reduction in the concentration of mature oligodendrocytes without a change in total glia cell concentration, and defects in myelin lamellar compaction and sheath thickness have been demonstrated [21].
To our knowledge, histopathological investigations of cerebral white matter lesions in immunohistochemically proven MDC1A of humans are confined to two reports. In an older study, a brain biopsy of a 14-year old girl with a condition consistent with MDC1A showed intact myelin sheaths but obvious astrocytic proliferation [22], in line with the present MRS observations. An autopsy study of a 4-month-old infant with merosin-deficient CMD revealed polymicrogyria and occipital agyria with marginal neuroglial heterotopia, but normal pattern of myelination consistent with early age [8].

There are only two previous reports on the use of MRS for a characterization of white matter alterations in MDC1A, both based on a determination of metabolite ratios. In a 4-year-old girl with MDC1A MRS of affected white matter revealed a normal NAA/Cr ratio and increased $\mathrm{Cho} / \mathrm{Cr}$ and $\mathrm{Ins} / \mathrm{Cr}$ ratios [23]. Similar results may be obtained for the present study when the quantitative metabolite concentrations are used to calculate ratios thereof. For example, the mean tNAA/ $\mathrm{tCr}$ concentration ratio of patients 4 and 5 in right and left white matter is 1.77 close to 1.65 obtained for age-matched controls (compare Table 2). In a more recent study using diffusion-weighted MRI and proton MRS of altered white matter in nine children with MDC1A the authors concluded that free-water concentrations are abnormally high in this condition [24]. This finding was based on reduced ratios of NAA $/ \mathrm{H}_{2} \mathrm{O}, \mathrm{Cr} /$ $\mathrm{H}_{2} \mathrm{O}$, Cho $/ \mathrm{H}_{2} \mathrm{O}$, and Ins $/ \mathrm{H}_{2} \mathrm{O}$ as well as on increased values of the apparent diffusion coefficient. Again in agreement with our results, MRS revealed normal $\mathrm{NAA} / \mathrm{Cr}$ and $\mathrm{Cho} / \mathrm{Cr}$ as well as slightly increased Ins/ $\mathrm{Cr}$ metabolite ratios. Our findings extend these reports because the determination of absolute metabolite concentrations allows for an unambiguous and specific assignment of the observed alterations to individual metabolites.

Macrocephaly in some patients and swelling of diffuse T2 hyperintensities in MDC1A point to edema of white matter. Reductions of the concentrations of most major metabolites, as demonstrated in this study, are consistent with white matter edema, if the normal concentrations of Ins are attributed to relative astrocytosis. This interpretation is in agreement with the hypothesis that laminin $\alpha 2$ deficiency results in leakage of fluids across the blood-brain barrier. Interestingly, the white matter alterations are not seen in compacted white matter such as the internal capsule or the corpus callosum. This observation is consistent with an edema rather than with a primary myelinopathy. Also the mild clinical signs of white matter dysfunction argue against a marked loss of vital neuroaxonal tissue.

We are not able to estimate the extent to which impaired myelin membrane formation due to laminin $\alpha 2$ deficiency may account for leukoencephalopathy in MDC1A. Dominant hypomyelination, however, is asso- 
ciated with a distinct MRS pattern different from that reported here, i.e. increased concentrations of tNAA, $\mathrm{tCr}$, and Ins together with a reduction of Cho as demonstrated in Pelizaeus-Merzbacher disease [25].

Our finding of largely normal spectra in cortical and subcortical grey matter is in line with the predominance of alterations in white matter well known from MRI studies of MDC1A. This difference is not explained by the fluid leakage hypothesis, as laminin $\alpha 2$ is expressed in the basal lamina of all cerebral blood vessels [18]. On the other hand, the relevance of laminin $\alpha 2$ for CNS myelination has been demonstrated in laminin $\alpha 2$ deficient mice, where defects in myelin lamellar compaction and sheath thickness have been observed [21]. We speculate that laminin $\alpha 2$ deficiency might lead to a locus minoris resistentiae in oligodendrocytes that facilitates leakage of water predominantly in white matter.

Clinical as well as MRI and MRS features of CNS alteration in laminin $\alpha 2$ deficiency show considerable overlap with those of megalencephalic leukoencephalopathy with subcortical cysts (MLC) [26,27]. Both conditions share in common early macrocephaly, extensive diffuse T2 hyperintensities of cerebral white matter that appears swollen, relatively mild signs of cerebral dysfunction, and a metabolic pattern comprising reduced tNAA, tCr, and Cho together with normal Ins. The MRS profile of white matter in MLC is in good agreement with the histopathological changes known to occur in this condition [28]. Histopathology revealed a cavitating spongiform leukoencephalopathy with vacuoles in the outermost lamellae of myelin sheaths. Subcortical white matter was altered by intense fibrillary astrogliosis, myelinated axons were well preserved [29]. Canavan disease $(C D)$ is a further condition characterized by macrocephaly and swollen white matter with marked T2 hyperintensity. MRS in CD, however, shows highly elevated tNAA due to a deficiency of aspartoacylase, and an osmotic-hydrostatic mechanism resulting from the continuous synthesis and efflux of NAA has been proposed to be responsible for the CD phenotype [30].

In summary, the present results corroborate previous views and provide additional insights in the metabolic changes occurring in laminin $\alpha 2$ deficiency in human brain. We emphasize the need for histopathological investigations of white matter alterations in MDC1A for a better understanding of the detailed pathophysiology.

\section{References}

[1] Colognato H, Yurchenco PD. Form and function: the laminin family of heterotrimers. Dev Dyn 2000;218:213-34.

[2] Tome FM, Evangelista T, Leclerc A, Sunada Y, Manole E, Estournet B, et al. Congenital muscular dystrophy with merosin deficiency. C R Acad Sci III 1994;317:351-7.
[3] Helbling-Leclerc A, Zhang X, Topaloglu H, Cruaud C, Tesson F, Weissenbach $\mathrm{J}$, et al. Mutations in the laminin alpha 2-chain gene (LAMA2) cause merosin-deficient congenital muscular dystrophy. Nat Genet 1995;11:216-8.

[4] Voit T. Congenital muscular dystrophies: 1997 update. Brain Dev 1998;20:65-74.

[5] van der Knaap MS, Smit LM, Barth PG, Catsman-Berrevoets $\mathrm{CE}$, Brouwer OF, Begeer JH, et al. Magnetic resonance imaging in classification of congenital muscular dystrophies with brain abnormalities. Ann Neurol 1997;42:50-9.

[6] Sunada Y, Edgar TS, Lotz BP, Rust RS, Campbell KP. Merosinnegative congenital muscular dystrophy associated with extensive brain abnormalities. Neurology 1995;45:2084-9.

[7] Philpot J, Cowan F, Pennock J, Sewry C, Dubowitz V, Bydder G, et al. Merosin-deficient congenital muscular dystrophy: the spectrum of brain involvement on magnetic resonance imaging. Neuromuscul Disord 1999;9:81-5.

[8] Taratuto AL, Lubieniecki F, Diaz D, Schultz M, Ruggieri V, Saccoliti M, et al. Merosin-deficient congenital muscular dystrophy associated with abnormal cerebral cortical gyration: an autopsy study. Neuromuscul Disord 1999;9:86-94.

[9] Jones KJ, Morgan G, Johnston H, Tobias V, Ouvrier RA, Wilkinson I, et al. The expanding phenotype of laminin alpha2 chain (merosin) abnormalities: case series and review. J Med Genet 2001;38:649-57.

[10] Frahm J, Michaelis T, Merboldt KD, Bruhn H, Gyngell ML, Hanicke W. Improvements in localized proton NMR spectroscopy of human brain. Water suppression, short echo times, and $1 \mathrm{ml}$ resolution. J Magn Reson 1990;90:464-73.

[11] Provencher SW. Estimation of metabolite concentrations from localized in vivo proton NMR spectra. Magn Reson Med 1993;30:672-9.

[12] Bjartmar C, Battistuta J, Terada N, Dupree E, Trapp BD. $N$ acetylaspartate is an axon-specific marker of mature white matter in vivo: A biochemical and immunohistochemical study on the rat optic nerve. Ann Neurol 2002;51:51-8.

[13] Urenjak J, Williams SR, Gadian DG, Noble M. Proton nuclear magnetic resonance spectroscopy unambiguously identifies different neural cell types. J Neurosci 1993;13:981-9.

[14] Griffin JL, Mann CJ, Scott J, Shoulders CC, Nicholson JK. Choline containing metabolites during cell transfection: an insight into magnetic resonance spectroscopy detectable changes. FEBS Lett 2001;509:263-6.

[15] Brand A, Richter-Landsberg C, Leibfritz D. Multinuclear NMR studies on the energy metabolism of glial and neuronal cells. Dev Neurosci 1993;15:289-98.

[16] Pouwels PJ, Brockmann K, Kruse B, Wilken B, Wick M, Hanefeld F, et al. Regional age dependence of human brain metabolites from infancy to adulthood as detected by quantitative localized proton MRS. Pediatr Res 1999;46:474-85.

[17] Frahm J, Hanefeld F. Localized proton magnetic resonance spectroscopy of brain disorders in childhood. In: Bachelard HS, editor. Magnetic resonance spectroscopy and imaging in neurochemistry. New York: Plenum; 1997. p. 329-402.

[18] Villanova M, Malandrini A, Sabatelli P, Sewry CA, Toti P, Torelli $\mathrm{S}$, et al. Localization of laminin alpha 2 chain in normal human central nervous system: an immunofluorescence and ultrastructural study. Acta Neuropathol (Berl) 1997;94:567-71.

[19] Caro PA, Scavina M, Hoffman E, Pegoraro E, Marks HG. MR imaging findings in children with merosin-deficient congenital muscular dystrophy. Am J Neuroradiol 1999;20:324-6.

[20] Buttery PC, ffrench-Constant C. Laminin-2/integrin interactions enhance myelin membrane formation by oligodendrocytes. Mol Cell Neurosci 1999;14:199-212.

[21] Chun SJ, Rasband MN, Sidman RL, Habib AA, Vartanian T. Integrin-linked kinase is required for laminin-2-induced oligoden- 
drocyte cell spreading and CNS myelination. J Cell Biol 2003;163:397-408.

[22] Egger J, Kendall BE, Erdohazi M, Lake BD, Wilson J, Brett EM. Involvement of the central nervous system in congenital muscular dystrophies. Dev Med Child Neurol 1983;25:32-42.

[23] Aslan M, Alkan A, Yakinci C, Sonmezgoz E, Bicak U, Zorludemir S. Merosin-negative congenital muscular dystrophy: magnetic resonance spectroscopy findings. Brain Dev 2005;27:308-10.

[24] Leite CC, Reed UC, Otaduy MC, Lacerda MT, Costa MO, Ferreira LG, et al. Congenital muscular dystrophy with merosin deficiency: 1H MR spectroscopy and diffusion-weighted MR imaging. Radiology 2005;235:190-6.

[25] Hanefeld FA, Brockmann K, Pouwels PJ, Wilken B, Frahm J, Dechent P. Quantitative proton MRS of Pelizaeus-Merzbacher disease: evidence for dys- and hypomyelination. Neurology 2005;65:701-6.

[26] van der Knaap MS, Barth PG, Stroink H, van Nieuwenhuizen O, Arts WF, Hoogenraad F, et al. Leukoencephalopathy with swelling and a discrepantly mild clinical course in eight children. Ann Neurol 1995;37:324-34.

[27] Leegwater PA, Yuan BQ, van der Steen J, Mulders J, Konst AA, Boor PK, et al. Mutations of MLC1 (KIAA0027), encoding a putative membrane protein, cause megalencephalic leukoencephalopathy with subcortical cysts. Am J Hum Genet 2001;68:831-8

[28] Brockmann K, Finsterbusch J, Terwey B, Frahm J, Hanefeld F. Megalencephalic leukoencephalopathy with subcortical cysts in an adult: quantitative proton MR spectroscopy and diffusion tensor MRI. Neuroradiology 2003;45:137-42.

[29] van der Knaap MS, Barth PG, Vrensen GF, Valk J. Histopathology of an infantile-onset spongiform leukoencephalopathy with a discrepantly mild clinical course. Acta Neuropathol (Berl) 1996;92:206-12.

[30] Baslow MH. Brain N-acetylaspartate as a molecular water pump and its role in the etiology of Canavan disease: a mechanistic explanation. J Mol Neurosci 2003;21:185-90. 